Weiss, S., Winter, R.: Development of Measurement Items for the

Institutionalization of Enterprise Architecture Management in Organizations, Aier,

S., Ekstedt, M., Matthes, F., Proper, E., Sanz, J. (Eds.): Trends in Enterprise

Architecture Research and Practice Driven Research on Enterprise Transformation, Barcelona, 23.10.2012, Springer, Berlin, Heidelberg, LNBIP 131, 2012, pp. 268-283., http://dx.doi.org/10.1007/978-3-642-34163-2_16

\title{
Development of Measurement Items for the Institutionalization of Enterprise Architecture Management in Organizations
}

\author{
Simon Weiss and Robert Winter \\ University of St. Gallen, Institute of Information Management \\ Mueller-Friedberg-Strasse 8, 9000 St. Gallen, Switzerland \\ \{simon.weiss, robert.winter\}@unisg.ch
}

\begin{abstract}
While elaborate enterprise architecture management (EAM) methods and models are at architects' disposal, it remains an observable and critical challenge to actually anchor, i.e. institutionalize, EAM in the organization and among non-architects. Based on previous work outlining design factors for EAM in light of institutional theory, this work discusses the theoretical grounding of respective design factors and proposes measurement items for assessing the institutionalization of EAM in organizations. The work identifies measurement items for the factors legitimacy, efficiency, stakeholder multiplicity, organizational grounding, goal consistency, content creation, diffusion and trust, contributing to evaluate and inform EAM design from several, partially new perspectives.
\end{abstract}

Keywords: Measurement items, Institutionalization, Enterprise Architecture Management

\section{Introduction}

At the core of this research lies the observable issue that an effective anchoring of EAM within the organization and in particular among non-architects remains a major challenge. This challenge is also well reflected in Gartner's recent reasoning for the finding that most analyzed organizations are still at a rather low EA maturity level [1]. This is despite the fact that EAM has become a maturing discipline in research as well as in practice, and a wide set of EAM methods, tools and best practices have been researched, developed and applied [2,3]. However, unless these methods are broadly supported and become operative, envisioned EA benefits will be limited or, for that matter, take much longer time for realization. One reason for the difficulties of such an anchoring of EAM may be that the immediate context of EAM, i.e. the way how and why the organization responds to the EAM approach on a normative level, is only little understood [4].

The paper at hand addresses this issue based on an institutional theory perspective, as it may be well applicable to inform and conceptualize an anchoring of EAM. Institutional theory is among other aspects concerned with the questions of how organiza- 
tions and individuals respond to pressures and what factors influence their conformance [5-7]. In our case we ask which design factors are important to anchor EAM and foster its acceptance, or said differently, which design factors should be obeyed in order to institutionalize EAM. Institutionalization can be defined as the process of establishing a practice as a norm thus giving it a "rulelike status in social thought and action" [8]. Under the assumption that EAM is being useful and adequately implemented such that it provide a positive contribution to the organizational development [9], this is what we should try to achieve. The term design factor is used to indicate our ultimate goal, namely the design of EAM. We are thus interested in factors that can actually be influence by the design of EAM as opposed to wider influencing factors which may also be important (e.g. world economy fluctuations), but which cannot be controlled nor be reasonably respected as part of our intra-organizational EAM context.

Fig. 1 illustrates the line of thought underlying this work: The upper bubbles represent directing functions that exert pressures onto the rest of the focal organization. A pressure can be a guideline, rule, norm or regulation, for example. Depending on the pressure's characteristics, the organization's response may range from acquiesce to defiance and manipulation of the pressure or the pressure exerting entity itself [7]. Clearly, obligations such as the necessity to keep track of financial spending coming from the controlling function, for example, are much more accepted and institutionalized than e.g. architecture principles coming from EAM. The focus of this research lies on the very left of the figure, asking which design factors are important to institutionalize EAM, i.e. to essentially foster positive rather than defying organizational responses.

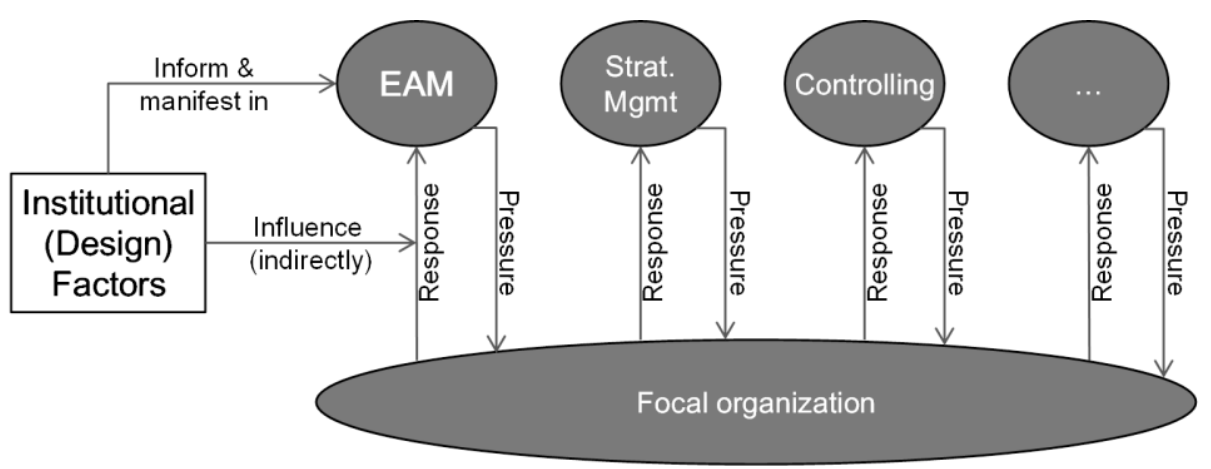

Fig. 1. Design Factors for EAM

The paper reports on research in progress towards an instrument providing guidance on how to institutionalize EAM in organizations. To that end, the work addresses in general two research gaps: From an institutional theory point of view, it applies the institutional perspective to the organization as level of analysis, thus aiming at understanding intra-organizational behavior. While previous institutional research at this level of analysis is very limited, it is believed to go far in adding to institutional theory [10]. From an EAM point of view, this work's perspective should contribute to 
better EAM design and an empowerment of existing EAM methods. Hjort-Madsen notes that an institutional perspective addressing economic, political and contextual factors as opposed to technical ones, is underrepresented in EA research so far [11, 12].

In conclusion, the goal of the paper at hand is to construct measurement items towards a theoretically grounded model of design factors for an institutionalization of EAM. These items should be the foundation of a model providing the utility to be able to analyze an organization's EAM approach and to subsequently derive important fields of action for improvement. The measurement item creation is based on previous work about relevant design factors. Following thorough methodological procedures for construct measurement, the paper (1) conceptualizes the constructs and (2) identifies measurement items based on reviews of the literature, deduction from the theoretical definition of the constructs and previous empirical research on the focal constructs [13-15]. ${ }^{1}$

The remainder of the paper is structured as follows. Chapter two outlines the theoretical and methodological foundations. Chapter three conceptualizes our design factors and discusses each factor and related measurement items. Chapter four concludes the paper with a discussion, limitations, and an outlook on evaluation procedures for the herein presented work.

\section{Theoretical Foundations and Relevant Factors}

\subsection{An Institutional Perspective on EAM}

In an IS context, institutional theory has been considered in many facets. Boudreau \& Robey [16], Markus \& Robey [17] for example argue that and how theories, including institutional theory, can contribute to questions of information technology and organizational change. In a similar vein, Orlikowski \& Barley [18] elaborate on the interplay between IT and organizational research, suggesting that transformations cannot be understood without considering their institutional contexts. Also, from a macro perspective, it has been analyzed which institutions influence (IT) innovations and how institutional pressures influence the adoption of respective systems [19, 20]. Another stream of research deals with processes of institutionalization of IT in organizations, with institutionalization and de-institutionalization processes and respective forces that drive such endeavors [21]. While being far from complete, this brief review shows that an institutional perspective is being considered important in the context of IS and (strategic) management.

Focused on the relationship between institutional theory and EAM the work by Hjort-Madsen stands out. Hjort-Madsen investigates how EA implementation [11] and adoption [12] is dependent upon and shaped by institutional forces, noting that this issue is underrepresented in EA research so far. Looking at public sector organi-

1 Methodologically-wise so called constructs are in our case instantiated by the aforementioned design factors, which can be regarded to embody our application domain and the deeper purpose. Both terms may be used interchangeably throughout this work, though. 
zations, Hjort-Madsen points out that interoperability and IS planning, which can be facilitated through EAM, is not only a technical issue, but economic, political and contextual factors are just as important. Related to different institutional settings, he identifies adoption patterns that describe how EA is adopted by agencies. By considering formerly ignored institutional pressures, he contributes to understanding and advancing EA as a transformation approach. However, his work stays on a descriptive-explorative level and focuses on pressures coming from the outside of the focal organization. In contrast to this, we intend to look at how institutional factors relate to an intra-organizational anchoring and acceptance of EAM, and how resulting insights can inform EAM design. Overall, we found that a concrete structuring of institutional factors influencing EAM in an intra-organizational context is lacking so far.

\subsection{Adopted Methodology}

For scale development, we adopt a combination of the approaches from Moore \& Benbasat [22], which can be regarded as a revised version of the methodological procedures from Davis [14], and the construct measurement and validation procedures from MacKenzie et al. [13]. The reason for a combination of both methods lies in the intention to utilize the strengths of both: Moore \& Benbasat's so called Instrument Development Process consists of three stages, which are well comprehensible and have gained wide acceptance among IS researchers, who adopted (and adapted) the approach to various contexts (e.g. [23]). The three stages are Item Creation, Scale Development and Instrument Testing. MacKenzie et al.'s “construct measurement and validation procedures" in turn represent a revised, complementary and more detailed guideline. They split the whole scale development process into ten steps and propose additional techniques for accomplishing certain steps. The paper at hand mainly deals with the Item Creation stage, which corresponds to step two ("Generate Items to Represent the Construct") of MacKenzie et al.'s [13] updated scale development procedure. The essence of the three stages is outlined in the following.

Item Creation is concerned with establishing a pool of items that can potentially describe a construct. An item is typically a statement that respondents can indicate their degree of agreement to. The goal of the phase is to ensure content validity, i.e. the intended content of a construct shall be adequately addressed, or represented, by the pool of measurement items. Adequately in this context means that the items shall be focused on the construct's domain, but fully capture all of the essential aspects of the construct while at the same time trying to minimize overlaps with other constructs. The items may come from a variety of sources such as literature, deduction from construct definition, empirical research or expert suggestions [13]. However, generated items should always be tailored to the research issue in question and thus follow Ajzen \& Fishbein's [24] suggestions to not only include the actual behavior (e.g. using EA), but also to respect the target at which the behavior is directed (e.g. EAM function), the context for the behavior (e.g. intra-organizational use of EAM services for transformation support), and a time frame (e.g. current, previous and planned EAM initiatives). Overall, we follow these guidelines, while trying to adopt measurement items that were rigorously derived and successfully applied in previous 
research as far as possible and feasible. The time frame is not explicitly included in our item specifications though, as we intend to examine the current situation in organizations only.

Scale Development aims at so called construct validity (cf. [22]). Using a certain technique, previously generated items are assessed by a group of (targeted) experts in order to achieve the following goals: 1) Convergent validity and discriminant validity, i.e. an item is consistently attributed to only one particular construct; 2) Appropriate coverage, i.e. removal or refinement of ambiguous, too similar or less relevant items. Many techniques have been developed to achieve construct validity, while two of them appear to have gained most prominence. The first technique resembles a "card sorting" exercise: Judges are asked to sort the various items into construct categories and rank how well the items fit the construct definitions. The procedure allows for multiple rounds and the option to present the definition of intended constructs upfront or to have the participants create their own labels for the constructs [14, 22]. In the second technique, the researcher creates a matrix with construct definitions at the top of the columns and items listed at the rows. Judges are then asked to rate in each cell how well an item fits the construct, typically using a five point Likert scale. The ratings are then evaluated using statistical means [13, 25].

Instrument Testing is then the last step towards a valid theoretical model. It is concerned with testing the developed scales (and potential construct relationships) at a higher sample size. However, provided that the previous phases are conducted rigorously, this phase should a) be limited to data gathering and evaluation, and b) be likely to yield good and significant results.

\section{Development of Measurement Items}

\subsection{Conceptualization of Constructs}

Prior to the aforementioned measurement item generation and scale development procedure, conceptual definitions of the constructs of interest have to be developed. A construct is a rather abstract, more general and latent variable that is not or hardly directly observable or measurable. A solid conceptualization of constructs has gained increased attention in literature. While Moore and Benbasat's frequently cited three stages instrument development process does not explicitly address construct conceptualization, MacKenzie et al. dedicate a detailed first step to it, noting that an adequate construct definition was a critical limitation of current scale development procedures and measurement model specifications. They critically note that "the failure to adequately specify the conceptual meaning of a study's focal constructs...triggers a sequence of events that undermines construct validity (primarily due to measure deficiency), statistical conclusion validity (due to the biasing effects of measurement model misspecification), and ultimately internal validity (due to a combination of factors)" [cf. 26]. In our attempt to avoid these problems, Table 1 portrays the design factors and their respective specification following respective conceptualization recommendations [13]. 
Our constructs have been developed in previous research [4] based on case study assessments and informed by the institutional framework from Oliver [7]. The constructs are to represent factors that influence stakeholders', i.e. in particular nonarchitects', perception and acceptance of EAM. Together, the factors can therefore be regarded as indicators for a successful institutionalization of EAM.

As previously mentioned, our long-term goal is to develop design principles that address these constructs and inform the design of EAM (according to the design science research paradigm [27]), which is why we refer to our constructs as design factors.

Table 1. Conceptualization of Design Factors

\begin{tabular}{|c|c|}
\hline EAM Design Factor & Specification \\
\hline Legitimacy & $\begin{array}{l}\text { Entity: Person; } \\
\text { General property: Perceived social rationale for participation (in EAM); } \\
\text { Themes: Management acknowledgement, reputation, social acceptance; } \\
\text { Definition: The degree to which a stakeholder gains social fitness when } \\
\text { supporting EAM. }\end{array}$ \\
\hline Efficiency & $\begin{array}{l}\text { Entity: Person; } \\
\text { General property: Perceived economic rationale for participation (in } \\
\text { EAM); } \\
\text { Themes: Decision making speed, project time, project sustainability, } \\
\text { implementation quality, utilization of available infrastruc- } \\
\text { ture/information; } \\
\text { Definition: The degree to which a stakeholder becomes more efficient } \\
\text { when following EA guidelines. }\end{array}$ \\
\hline
\end{tabular}




\begin{tabular}{|l|l|}
\hline EAM Design Factor & Specification \\
\hline Coordination of \\
Pressure Multiplicity & $\begin{array}{l}\text { Entity: Organization; } \\
\text { General property: Potential for inconsistencies/conflicts with other di- } \\
\text { recting entities depending upon the amount of coordinating action; } \\
\text { Themes: Alignment with other coordinating functions (e.g. process man- } \\
\text { agement), alignment of different EAM divisions/levels, centrality of EA } \\
\text { decision making; } \\
\text { Definition: The degree to which the focal EAM is aligned with other } \\
\text { pressure exerting entities. } \\
\text { Entity: Organization; } \\
\text { General property: Organizational anchor points (for EAM); } \\
\text { Themes: Stakeholder demand, strategic importance, hierarchical posi- } \\
\text { tion; } \\
\text { Definition: The degree to which EAM is grounded at different anchor } \\
\text { points within the organization } \\
\text { Entity: Person; } \\
\text { General property: Characteristics of goal system; } \\
\text { Themes: Stakeholders' knowledge about others' transformation activi- } \\
\text { Thest } \\
\text { ties, design of stakeholder goal systems, raise/promotion; } \\
\text { Definition: The degree to which EA goals are in line with / supported by } \\
\text { stakeholders' goals. } \\
\text { Entity: Process; } \\
\text { General property: Stakeholder-orientation in EA content creation activi- } \\
\text { ties; } \\
\text { Themes: Availability of stakeholder-involving processes, participation of } \\
\text { stakeholders, contribution channels, approval of stakeholders; } \\
\text { Definition: The degree to which EA content creation processes cater for } \\
\text { stakeholder involvement. } \\
\text { Entity: Process/Team; } \\
\text { General property: Communication and diffusion activities; } \\
\text { Themes: Propagation of the EA idea, availability of showcases, commu- } \\
\text { nication procedures; } \\
\text { Definition: The degree to which (voluntary) EA participation is fostered } \\
\text { by communication. } \\
\text { Entity: Person; } \\
\text { General property: Attitude / Trustworthiness (of the EAM function); } \\
\text { Themes: Trust in EAM as instrument, trust in EAM team; } \\
\text { Definition: The degree to which stakeholders have trust in EAM. }\end{array}$ \\
\hline
\end{tabular}

Besides a label (column1), column two specifies the construct with respect to four dimensions. The entity is the object that is in focus of the construct, i.e. it is the object to which the general property applies and that is eventually addressed by measurement items. The general property refers to the conceptual domain of the construct. This should be specified, because it may make a considerable difference whether the construct is to represent a (subjective) perception or an as far as possible objective outcome, for example [13, citing 28]. In our case, we may differentiate two major groups of constructs. On the one hand, we have constructs addressing personal perceptions or feelings towards EAM such as the potential to gain legitimacy, become more efficient, or one's personal trust towards EAM. On the other hand, we have 
constructs which address the wider EAM setup and are attributed the entities organization, process, or team, accordingly. Examples are coordination activities, grounding, as well as content creation or diffusion activities. Goal consistency may be regarded to be a special case as it is to some extent concerned with clearly defined, jobrelated performance goals. However, the extent to which EAM goals are intrinsically or extrinsically supported by an individual is a personal matter, which is why we have attributed the construct to the entity person. The themes then portray the line of thought and the aspects of the construct, which will subsequently be captured by the measurement items. At last, the definition is intended to wrap up all these aspects in a short and understandable manner. Based on this construct conceptualization, the following section will have a closer look at how each construct can be measured.

\subsection{Generation of Measurement Items}

Items were created based on literature and domain knowledge. Starting from a search for measurement scales in the IS domain, the search was continued in an explorative fashion including a wider range of other research domains such as business administration, management, psychology and politics. The search was conducted using EBSCO and google scholar using key words from the construct descriptions and the terms "measurement", "scale" or "model". The search was limited to title, keywords and abstract. The more explorative approach taken appeared reasonable as our primary goal was to first of all generate feasible items rather than validate them [21]. The last column (Adoption Type (AT)) of the measurement item tables below indicates to which extent a scale could be adopted:

1. Construct and context fit - Items fit to our factor's purpose, and the context is (closely) related to EAM and/or an intra-organizational institutional perspective.

2. Construct fits - Items fit to our factor's purpose, but the context is different.

3. Analogy - Items can be adapted based on our construct's conceptualization.

Legitimacy in our case refers to the amount of social fitness or acceptance that an individual gains when contributing to an advancement of the enterprise architecture. Addressing personal social benefit expectancy, the items for this factor can be well drawn from Venkatesh et al.'s work, which in turn already consolidates previous measurement items. Of particular relevance appear items from performance expectancy and social influence (see Table 2) [15]. Legitimacy in general is acknowledged as an important concept for explaining a wide range of effects such as desirability, credibility and appropriateness [29]. We hypothesize this to be relevant for EAM, too [30]. 
Table 2. Measurement Items for (Social) Legitimacy

\begin{tabular}{|l|l|l|l|}
\hline No & Item definition & Source(s) & AT \\
\hline LE1 & People who are important to me think that I should mind EAM. & {$[15]$} & 2 \\
\hline LE2 & Minding EA is acknowledged by my superiors. & {$[15,31]$} & 2 \\
\hline LE3 & Senior management supports me in advancing EA. & {$[15,31]$} & 2 \\
\hline LE4 & In general, the organization supports EAM. & {$[15,31]$} & 2 \\
\hline LE5 & People minding EAM have more prestige than those who do not. & {$[15,22]$} & 2 \\
\hline LE6 & People minding EAM have a high profile. & {$[15,22]$} & 2 \\
\hline
\end{tabular}

Efficiency is related to economic accountability and rationalization on a personal perceptional level. In a similar fashion, this factor is also regularly part of eventual EA benefit measurement, representing a main rationale to run EAM programs in the first place [cf. 32, 33]. However, in our case the factor is targeted at stakeholder perception (entity=person). As such, we may again draw some items from Venkatesh et al. [15]. The last two items though are novel and intended to address specific EAM concerns (Table 3).

Table 3. Measurement Items for Efficiency

\begin{tabular}{|l|l|l|l|}
\hline No & Item definition & Source(s) & AT \\
\hline EF1 & $\begin{array}{l}\text { Minding EAM allows accomplishing decision making for trans- } \\
\text { formation projects more quickly. }\end{array}$ & $\begin{array}{l}{[14,15,} \\
22]\end{array}$ & 2 \\
\hline EF2 & $\begin{array}{l}\text { Minding EAM allows completing transformation projects more } \\
\text { quickly. }\end{array}$ & $\begin{array}{l}{[14,15,} \\
22]\end{array}$ & 2 \\
\hline EF3 & $\begin{array}{l}\text { Minding EAM increases the quality of output of transformation } \\
\text { projects. }\end{array}$ & {$[15,31]$} & 2 \\
\hline EF4 & Minding EAM increases the sustainability of project outputs. & {$[15,31]$} & 3 \\
\hline EF5 & $\begin{array}{l}\text { Using EAM reduces the time needed for data gathering required } \\
\text { for transformation projects. }\end{array}$ & {$[15,31]$} & 2 \\
\hline EF6 & Minding EAM takes too long. & {$[15,31]$} & 2 \\
\hline EF7 & $\begin{array}{l}\text { Using EAM allows making use of available infrastructure effi- } \\
\text { ciently. }\end{array}$ & & \\
\hline EF8 & $\begin{array}{l}\text { Using EAM allows making use of available transformation } \\
\text { knowledge efficiently. }\end{array}$ & & \\
\hline
\end{tabular}

Multiplicity refers to directions, strengths, and synergies of interacting stakeholder claims [34]. We apply this thought to EAM. Besides EAM, constituents like strategic management, controlling, HR, and IT exert pressures on each other and the focal organization as a whole with respect to requirements, releases, project portfolios, business development etc. A major challenge of EAM operating at the nexus of Business and IT is to coordinate and line up with all these pressure exerting entities in order to become more effective and to increase its penetration. We hypothesize that if such coordination is low, EA development will be less aligned and in consequence, EAM's voice will also be less heard among non-architects and project managers (e.g. due to conflicting development objectives). After all, the latter aspect appears to be critical but a major challenge, as EAM is a rather young (and thus less institutionalized) enterprise function as opposed to controlling, for example. Not surprisingly then, we could so far hardly find measurement scales that fit our construct (Table 4). 
Table 4. Measurement Items for Multiplicity

\begin{tabular}{|l|l|l|l|}
\hline No & Item definition & Source(s) & AT \\
\hline MU1 & EAM is coordinated with other management functions. & & \\
\hline MU2 & Different EAM units are aligned to each other. & & 1 \\
\hline MU3 & $\begin{array}{l}\text { EAM decision making is done centrally, involving a multiplicity } \\
\text { of stakeholders / business units. }\end{array}$ & {$[33]$} & $\begin{array}{l}\text { Bodies for the coordination of EAM concerns (e.g. EAM board) } \\
\text { are formally established. }\end{array}$ \\
\hline MU4 & $\begin{array}{l}\text { Considerable differences exist between the EA function and other } \\
\text { business units with respect to EA development. }\end{array}$ & \\
\hline MU5
\end{tabular}

Grounding refers to the anchoring points of EAM within the organization, which can be decomposed into two distinguishable facets or sub-dimensions (Table 5): GR1-3 refer to the demand side of EAM. They intend to elicit who the demanders of EAM in the organization are, i.e. who is actually interested in and makes use of EAM services. To that end, we differentiate between three classical EAM stakeholder groups - (1) business units, (2) IT and (3) senior management. GR4-6 then relate to some extent to governance issues, asking how possibly restricting guidelines EAM may impose are grounded. Like the previous factor (multiplicity), grounding appears to be very EAMspecific by relating to cross-functional and cross-level issues.

Table 5. Measurement Items for Grounding

\begin{tabular}{|l|l|l|l|}
\hline No & Item definition & Source(s) & AT \\
\hline GR1 & EAM is called for by business units. & & \\
\hline GR2 & EAM is called for by the IT function. & & \\
\hline GR3 & EAM is called for by senior management. & & \\
\hline GR4 & $\begin{array}{l}\text { EAM is positioned high in the organizational hierarchy (organi- } \\
\text { gram). }\end{array}$ & & \\
\hline GR5 & EAM guidelines are grounded in the overall business strategy. & & \\
\hline GR6 & EAM guidelines are grounded in the IT strategy. & & \\
\hline
\end{tabular}

Goal Consistency refers to the congruence of EA goals and individual stakeholders' goals, such as project managers. This, ideally, also includes awareness between stakeholders about their respective goals and transformation intentions, as this may provide opportunities to consult EAM to help leverage synergies - for instance by coordinating (joint) projects of multiple business units. The last two items address personal career goals more directly (Table 6). In previous research, goal congruence has in varying settings been identified as a significant thruster for goal achievement [35, 36]. Overall, goal consistency is very relevant for EAM, as a major goal of EAM is to leverage synergies across projects. However, even if the top management directive was to maximize the benefit for the whole organization, this will be difficult to achieve without additional incentives. As repeatedly experienced with industry partners, a project manager will be reluctant to spend $\$ 10 \mathrm{M}$ more, even if it would save another unit $\$ 20 \mathrm{M}$. 
Table 6. Measurement Items for Goal Consistency

\begin{tabular}{|c|c|c|c|}
\hline No & Item definition & Source(s) & AT \\
\hline $\mathrm{CO} 1$ & Stakeholders know about other units' goals. & & \\
\hline $\mathrm{CO} 2$ & Stakeholders know about other units' transformations. & & \\
\hline $\mathrm{CO} 3$ & $\begin{array}{l}\text { EAM goals are supported by non-architects' goal system formula- } \\
\text { tion. }\end{array}$ & & \\
\hline $\mathrm{CO} 4$ & $\begin{array}{l}\text { EAM goals are explicitly addressed in non-architects' goal system } \\
\text { formulation. }\end{array}$ & & \\
\hline $\mathrm{CO5}$ & $\begin{array}{l}\text { Non-architects have incentives to pursue cross-project or cross- } \\
\text { departmental goals. }\end{array}$ & & \\
\hline CO6 & $\begin{array}{l}\text { Minding EAM will increase stakeholders' chances of obtaining a } \\
\text { promotion. }\end{array}$ & {$[15,37]$} & 2 \\
\hline $\mathrm{CO} 7$ & $\begin{array}{l}\text { Minding EAM will increase stakeholders' chances of getting a } \\
\text { raise. }\end{array}$ & {$[15,37]$} & 2 \\
\hline
\end{tabular}

Content Creation items are intended to capture two related issues, namely if defined processes exist for content creation and whether stakeholder participation is explicitly part of these processes. For one, we ask whether stakeholders participate in content creation and approval, which is also addressed in related literature (Table 7). Overall though, we relate this to the question of whether participation processes are properly defined (entity=process). This link is based on the observation that participation (or at least approval) is frequently catered for and appreciated, but defined processes and EAM reviews as part of which participation happens may be lacking. In consequence to the latter, (proactive) contributions from non-architects are limited, handled nontransparently and may eventually come to an end, which in turn is contra-productive to the outset objective, namely fostering an institutionalization of EAM.

Table 7. Measurement Items for Content Creation

\begin{tabular}{|l|l|l|l|}
\hline No & Item definition & Source(s) & AT \\
\hline CR1 & EA content is developed with all relevant stakeholders. & & \\
\hline CR2 & EA content is approved (signed off) by all relevant stakeholders. & {$[33]$} & 1 \\
\hline CR3 & $\begin{array}{l}\text { Adequate stakeholder participation is ensured as part of EAM pro- } \\
\text { cesses. }\end{array}$ & {$[33]$} & 1 \\
\hline CR4 & $\begin{array}{l}\text { Stakeholder participation (e.g. making architectural suggestions) is } \\
\text { facilitated through defined channels and processes. }\end{array}$ & & \\
\hline CR5 & EAM guidelines are regularly reviewed. & $\begin{array}{l}\text { Exceptions to EAM guidelines are discussed through defined chan- } \\
\text { nels and processes. }\end{array}$ & \\
\hline CR6
\end{tabular}

Diffusion is to address what is done to make stakeholders aware of EAM services in order to foster their diffusion. Due to the challenges that a) EAM is oftentimes a rather young function within the organizations, b) EAM is concerned with partially abstract issues, and c) Architects are often occupied with operative work or project work, EAM communication is frequently lacking. However, making non-architects aware of EAM is an important antecedent to EAM demand and EAM penetration. The last two items capture a particular sub-aspect, namely the extent to which 'allied' non-architects signify that EAM is a good idea. 
Table 8. Measurement Items for Diffusion

\begin{tabular}{|l|l|l|l|}
\hline No & Item definition & Source(s) & AT \\
\hline DI1 & EA documents are communicated to all relevant stakeholders. & {$[33]$} & 3 \\
\hline DI2 & EA documents can be accessed easily by all relevant stakeholders. & {$[33]$} & 3 \\
\hline DI3 & Showcases demonstrating the necessity for EAM are available. & & \\
\hline DI4 & $\begin{array}{l}\text { Showcases demonstrating the necessity for EAM are effectively } \\
\text { communicated. }\end{array}$ & & \\
\hline DI5 & Showcases demonstrating success stories of EAM are available. & & \\
\hline DI6 & $\begin{array}{l}\text { Showcases demonstrating success stories of EAM are effectively } \\
\text { communicated. }\end{array}$ & & \\
\hline DI7 & It is defined how and which EA documents are communicated. & & \\
\hline DI8 & Non-architects promote the EA idea. & & \\
\hline DI9 & Non-architects promote EA content. & & \\
\hline
\end{tabular}

Trust has been added as dedicated factor even though one may argue that trust is indirectly reflected by all other factors. However, this factor shall in particular capture non-architects' attitude towards EAM as instrument and the architecture team behind it, which may for example also include personal trust relationships not explicitly addressed in previous factors. In consequence, the construct is clearly comprised of two sub-dimensions. The first (TR1 \& TR2) addresses trust in EAM as an instrument in general, whereas the second (TR3-17) is more related to interpersonal trust and trust in the EAM team, respectively. With respect to the second sub-dimension, many measurement items could be adopted from two major sources. Weatherford's work is actually concerned with political legitimacy, which, however, comprises several briefly and well-worded measurement items that appear to 'hit the nail on the head' - also in our setting (see TR3-8) [38]. Serva et al. investigated trust between interacting teams, i.e. between management and development teams. Their scales cover the facets of ability (here TR9-11), benevolence (here TR12-14), and integrity (here TR15-17) $[39,40]$. Analogously, we intend to examine trust between the EAM team and affected non-architects. All potential measurement items are presented in Table 9 for completeness and integrity purposes. We are aware though that this large amount of items has to be condensed considerably in order to be manageable for future probing. However, we decided to do that in conjunction with industry input as part of further research rather than limiting results in this work upfront.

Table 9. Measurement Items for Trust

\begin{tabular}{|l|l|l|l|}
\hline No & Item definition & Source(s) & AT \\
\hline TR1 & $\begin{array}{l}\text { Non-architects trust EAM to be a reasonable instrument for the } \\
\text { organization }\end{array}$ & {$[38]$} & 2 \\
\hline TR2 & Non-architects believe that EAM wastes a lot of money. & {$\left[\begin{array}{l} \\
\hline\end{array}\right.$}
\end{tabular}




\begin{tabular}{|l|l|l|l|}
\hline No & Item definition & Source(s) & AT \\
\hline TR3 & $\begin{array}{l}\text { Non-architects believe that Architects do not care much about what } \\
\text { non-architects think. }\end{array}$ & {$[38]$} & 2 \\
\hline TR4 & Non-architects trust EAM to do what is right. & {$[38]$} & 2 \\
\hline TR5 & Non-architects believe that EAM is just looking out for itself. & {$[38]$} & 2 \\
\hline TR6 & Non-architects believe that EAM is run for non-architects' benefit. & {$[38]$} & 2 \\
\hline TR7 & $\begin{array}{l}\text { Non-architects believe that the people running EAM are competent } \\
\text { and know what they do. }\end{array}$ & {$[38]$} & 2 \\
\hline TR8 & Non-architects feel taken seriously by the EAM team. & {$[38]$} & 3 \\
\hline TR9 & $\begin{array}{l}\text { Non-architects feel that the EAM team is very capable of perform- } \\
\text { ing its job. }\end{array}$ & {$[39]$} & 2 \\
\hline TR10 & Non-architects have confidence in the skills of the EAM team. & {$[39]$} & 2 \\
\hline TR11 & Non-architects believe that the EAM team is well qualified. & {$[39]$} & 2 \\
\hline TR12 & $\begin{array}{l}\text { The EAM team really looks out for what is important to non- } \\
\text { architects. }\end{array}$ & {$[39]$} & 2 \\
\hline TR13 & $\begin{array}{l}\text { Non-architects' needs and desires are very important to the EAM } \\
\text { team. }\end{array}$ & {$[39]$} & 2 \\
\hline TR14 & The EAM team goes out of its way to help non-architects. & {$[39]$} & 2 \\
\hline TR15 & $\begin{array}{l}\text { Non-architects believe that the EAM team tries to be fair in deal- } \\
\text { ings with others. }\end{array}$ & {$[39]$} & 2 \\
\hline TR16 & The EAM team has a strong sense of justice. & {$[39]$} & 2 \\
\hline TR17 & Non-architects like the values of the EAM team. & {$[39]$} & 2 \\
\hline
\end{tabular}

\section{Discussion and Outlook}

Reflecting on the up to this point established measurement items yields two findings. Firstly, it was hardly possible to find constructs or a set of measurement items in literature that perfectly fit our purposes. This may among other things be related to the history of research of the two research domains the paper at hand builds upon: With respect to EAM research, in-depth assessments of success and acceptance factors for EAM using sophisticated measurement scales still appears to be in its infancy. While first results to that end exist $[32,33]$, previous research was primarily focused on technical, methodological and governance issues from a rather managerial perspective. Institutional theory in turn was rarely applied to an intra-organizational context, and quantitative assessments of institutional constructs appear to be limited. As a consequence for the presented measurement items, these issues meant that also in cases where constructs were semantically similar (e.g. legitimacy or efficiency), items had to be reasonably selected rather than being able to adopt a whole construct conceptualization including its items at once. Secondly, items may overlap with other constructs. While trying to develop items through appropriate planning and rigorous procedures rather than through ex post testing in order to increase convergent and discriminant validity and coverage up front, this cannot be excluded yet, but has to be developed through further research including practice evaluations, using one of the techniques described in chapter two. At last, we would like to note that we make no claim for completeness with respect to identified measurement items, which would appear to be a bold and hardly provable claim given the wickedness of the problem at 
hand. We may have missed literature to provide further measurement items for our constructs, in particular because appropriate measurement items adoptable to our purpose may appear in a wider range of research fields. Also, the conceptualization of our constructs and the related search procedure may have limited our results. However, we are confident to have covered a thorough spectrum of important constructs and items, and to be able resolve ambiguities and increase the stability of our items when iteratively developing final scales.

Despite these limitations, the paper at hand contributes to stakeholder-oriented EAM research and to institutional theory. The paper advances research of how an institutional perspective can be concretized and inform another discipline. Especially an organization-internal application of institutional theory is so far very limited in previous research [10]. To that end, we hope to have contributed to this level of institutional analysis' body of knowledge. For practitioners and the EAM knowledge base, we think that our approach provides a differentiated and worthwhile perspective, namely addressing in particular normative factors and perceptions of EAM stakeholders. Concerning the utility for practitioners, the identified design factors should allow for a differentiated reflection of norms and values attributed to EAM by stakeholders, notwithstanding the fact that final and validated measurement scales, or, for that matter, a complete theoretical model, are still pending. However, despite of this lack of validation of the proposed constructs and measurement items, the herein presented perspective may be relevant and worth a discussion at this stage.

This being said, future research needs to first of all assess the proposed items and constructs with respect to construct validity, i.e. stage two of Moore \& Benbasat's procedure has to be conducted. As described in chapter two, good methodological reference literature on how and with which potential techniques to proceed exist to that end. As part of ongoing research, the development of scales as well as a theoretical model is currently in progress in an iterative fashion, using the 'matrix technique' and results from a first questionnaire-based survey. Concerning the former, a matrix is being created with construct definitions at the top of the columns and items listed at the rows. Judges consisting of academic scholars as well as professionals are then asked to rate in each cell how well an item fits the construct, using a five point Likert scale ranging from 1 (not at all) to 5 (completely). A one-way repeated measures ANOVA should then be used to assess whether an item's mean rating on one design factor differs from its ratings on other design factors [cf. 13]. In a related, parallel stream of research, we asked professionals about their status of establishing EAM. The survey comprised questions pertaining to institutional factors, stakeholder responses, organizational culture and the realized utility of EAM. Results from this survey are expected to triangulate and inform scale development for the herein discussed institutional design factors. First results from 90 respondents look promising. Based on resulting insights from these two approaches, we will then develop design principles for EAM that address the critical design factors such that EAM may become more operative within organizations.

\section{Acknowledgement}

This work has been supported by the Swiss National Science Foundation (SNSF). 


\section{References}

1. Gartner, I.: ITScore Overview for Enterprise Architecture. Gartner, Inc., Stamford, CT (2012)

2. Mykhashchuk, M., Buckl, S., Dierl, T., Schweda, C.M.: Charting the Landscape of Enterprise Architecture Management. In: The 10th International Conference on Wirtschaftsinformatik WI 2.011, Zurich (2011) 570-577

3. Buckl, S., Schweda, C.M.: On the State-of-the-Art in Enterprise Architecture Management Literature. Munich (2011)

4. Aier, S., Weiss, S.: An Institutional Framework for Analyzing Organizational Responses to the Establishment of Architectural Transformation. In: The 20th European Conference on Information Systems, Barcelona (2012)

5. Zucker, L.G.: Institutional Theories of Organization. Annual Review of Sociology 13, (1987) 443-464

6. Scott, W.R.: Institutions and Organizations: Ideas and Interests. Sage Publications, London (2008)

7. Oliver, C.: Strategic Responses to Institutional Processes. Academy Of Management Review 16, (1991) 145-179

8. Meyer, J.W., Rowan, B.: Institutionalized Organizations: Formal Structure as Myth and Ceremony. American Journal of Sociology 83, (1977) 340-363

9. Aier, S., Gleichauf, B., Winter, R.: Understanding Enterprise Architecture Management Design - An Empirical Analysis. In: The 10th International Conference on Wirtschaftsinformatik WI 2.011, Zurich (2011) 645-654

10. Greenwood, R., Oliver, C., Suddaby, R., Sahlin-Andersson, K. (eds.) The SAGE Handbook of Organizational Institutionalism. Sage Publications, London (2008)

11. Hjort-Madsen, K.: Enterprise Architecture Implementation and Management: A Case Study on Interoperability. IEEE Computer Society Press, Hawaii (2006) 71c

12. Hjort-Madsen, K.: Institutional patterns of enterprise architecture adoption in government. Transforming Government: People, Process and Policy 1, (2007) 333-349

13. MacKenzie, S.B., Podsakoff, P.M., Podsakoff, N.P.: Construct Measurement and Validation Procedures in MIS and Behavioral Research: Integrating New and Existing Techniques. MIS Quarterly 35, (2011) 293-334

14. Davis, F.D.: Perceived Usefulness, Perceived Ease of Use, and User Acceptance of Information Technology. MIS Quartely 13, (1989) 318-340

15. Venkatesh, V., Morris, M.G., Davis, G.B., Davis, F.D.: User Acceptance of Information Technology: Toward A Unified View. MIS Quarterly 27, (2003) 425-478

16. Boudreau, M.-C., Robey, D.: Coping with contradictions in business process reengineering. Information Technology \& People 9, (1996) 40-57

17. Markus, M.L., Robey, D.: Information Technology and Organizational Change - Causal Structure in Theory and Research. Management Science 34, (1988) 583-598

18. Orlikowski, W.J., Barley, S.R.: Technology and Institutions: What Can Research on Information Technology and Research on Organizations Learn From Each Other? MIS Quarterly 25 , (2001) $145-165$

19. King, J.L., Gurbaxani, V., Kraemer, K.L., McFarlan, F.W., Raman, K.S., Yap, C.S.: Institutional Factors in Information Technology Innovation. Information Systems Research 5, (1994) 139-169

20. Teo, H.H., Wei, K.K., Benbasat, I.: Predicting intention to adopt interorganizational linkages: an institutional perspective. MIS Quarterly 27, (2003) 19-49 
21. Baptista, J.J.: Institutionalisation as a process of interplay between technology and its organisational context of use. Journal Of Information Technology 24, (2009) 305-319

22. Moore, G., Benbasat, I.: Development of an instrument to measure the perceptions of adopting an information technology innovation. Information Systems Research 2, (1991) 192-222

23. Recker, J., Rosemann, M.: Understanding the Process of Constructing Scales Inventories in the Process Modelling Domain. In: European Conference on Information Systems (ECIS), St. Gallen, Switzerland (2007) Paper 8

24. Ajzen, I., Fishbein, M.: Understanding Attitudes and Predicting Social Behavior. PrenticeHall, Englewood Cliffs (1980)

25. Hinkin, T.R., Tracey, J.B.: An Analysis of Variance Approach to Content Validation. Organizational Research Methods 2, (1999) 175-186

26. MacKenzie, S.B.: The Dangers of Poor Construct Conceptualization. Journal of the Academy of Marketing Science 31, (2003) 323-326

27. Hevner, A.R., Chatterjee, S.: Design Research in Information Systems: Theory and Practice, vol. 22. Springer US, Dordrecht, Heidelberg, London, New York (2010)

28. Schwab, D.P.: Construct Validity in Organizational Behavior. In: Staw, B.M., Cummings, L.L. (eds.): Research in Organizational Behavior. JAI Press, Greenwich, CT (1980) 3-43

29. Suchman, M.C.: Managing Legitimacy: Strategic and Institutional Approaches. Academy Of Management Review 20, (1995) 571-610

30. Aier, S., Weiss, S.: Facilitating Enterprise Transformation Through Legitimacy - An Institutional Perspective. In: Multikonferenz Wirtschaftsinformatik 2012. Gito, Braunschweig (2012) 1073-1084

31. Thompson, R.L., Higgins, C.A., Howell, J.M.: Personal Computing: Toward a Conceptual Model of Utilization. MIS Quarterly 15, (1991) 125-143

32. Foorthuis, R., van Steenbergen, M., Mushkudiani, N., Bruls, W., Brinkkemper, S., and Bos, R.: On Course, but Not There Yet: Enterprise Architecture Conformance and Benefits in Systems Development. (2010)

33. Schmidt, C., Buxmann, P.: Outcomes and success factors of enterprise IT architecture management: empirical insight from the international financial services industry. European Journal Of Information Systems 20, (2011) 168-185

34. Neville, B.A., Menguc, B.: Stakeholder Multiplicity: Toward an Understanding of the Interactions between Stakeholders. Journal of Business Ethics 66, (2006) 377-391

35. Jauch, L.R., Osborn, R.N., Terpening, W.D.: Goal Congruence and Employee Orientation: The Substitution Effect. Academy Of Management Journal 23, (1980) 544-550

36. Kristof-Brown, A.L., Stevens, C.K.: Goal congruence in project teams: Does the fit between members' personal mastery and performance goals matter? Journal of Applied Psychology 86, (2001) 1083-1095

37. Compeau, D., Higgins, C.A., Huff, S.: Social Cognitive Theory and Individual Reactions to Computing Technology: A Longitudinal Study. MIS Quarterly 23, (1999) 145-158

38. Weatherford, M.S.: Measuring Political Legitimacy. The American Political Science Review 86, (1992) 149-166

39. Serva, M.A., Fuller, M.A., Mayer, R.C.: The reciprocal nature of trust: a longitudinal study of interacting teams. Journal of Organizational Behavior 26, (2005) 625-648

40. Mayer, R.C., Davis, J.H., Schoorman, F.D.: An Integrative Model of Organizational Trust. The Academy of Management Review 20, (1995) 709-734 